\title{
5
}

\section{Philosophy of Perception as a Guide to Aesthetics}

\author{
Bence Nanay
}

\subsection{The Provocative Claim}

The aim of this paper is to argue for a provocative claim: that many, maybe even most traditional problems in aesthetics are in fact about philosophy of perception and can, as a result, be fruitfully addressed with the help of the conceptual apparatus of the philosophy of perception. I will spend much of the paper clarifying and qualifying this claim, which after all the qualifications may not sound so provocative after all.

I need to clarify the following aspects of this claim:

(a) What is meant by aesthetics.

(b) What is meant by philosophy of perception.

(c) Why should we accept that it is a promising avenue of research to consider problems in aesthetics to be really about the philosophy of perception.

I will take these in turn. But before we begin, it needs to be emphasized that on the face of it, the claim I make does not sound crazy, at least if we consider the etymology of the term 'aesthetics'. The Greek word 'aesthemi' means perception and when Alexander Baumgarten introduced the concept of 'aesthetics' in 1750, what he meant by it was precisely the philosophy of perception: the study of sense perception (scientia cognitionis sensitivae). My claim is that, regardless of etymology, this connection can also be made today.

It is important that my aim is not to argue that aesthetics should be a subdiscipline of philosophy of perception or that any approach that does not consider aesthetics to be philosophy of perception is doomed or should be considered inferior. The aim of the paper is more modest (and less imperial): it is to convince the reader that many (not all) traditional problems in aesthetics can be efficiently addressed in a philosophy of perception framework (see also Nanay 2014). 


\subsection{Aesthetics versus Philosophy of Art}

First important qualification: my claim is about aesthetics and not about the philosophy of art. I do not suggest that it is a promising avenue of research to consider problems in the philosophy of art to be really about the philosophy of perception-it would be difficult to defend this claim. The philosophy of art, like any philosophy of X, asks a wide variety of questions about $\mathrm{X}$-about art in this case. Some of these questions are metaphysical, some others epistemological, political, or ethical. I will try to say as little about the philosophy of art here as possible.

As it has been repeatedly pointed out, aesthetics and the philosophy of art are very different disciplines. The most important attempts to draw a line between aesthetics and the philosophy of art were fuelled by a certain mistrust of things aesthetic. The general line of argument, by Dickie and Carroll, among others (Dickie 1964, 1974; Carroll 2000, 2001), is that too much attention has been given to 'the aesthetic' in the discussion of art. Aesthetic response (or aesthetic experience or aesthetic appreciation, whatever any of these concepts may mean) is only one possible response to art (even if we can make sense of what these concepts mean). Thus, they conclude, when we discuss philosophy of art, we are better off doing so without any necessary reference to aesthetics.

I want to use this argument in the opposite way from the way the opponents of aesthetics originally intended. As I want to talk about aesthetics, if I want to follow the logic of the Dickie- and Carroll-style arguments, I may be better off doing so with no necessary reference to art built into the concept of aesthetics. This is already a significant step towards the main claim of the paper: we should detach aesthetics from art, but do so carefully.

A consequence of this is that we should not build in a necessary reference to art in the definition of the aesthetic domain. Nor should we, of course, build in a necessary reference to the philosophy of perception, if we want to avoid circularity. I use a simple and pedestrian route and define the domain of aesthetics as the sum total of topics where we use the term 'aesthetic'. This would involve (but of course not be limited to) debates about aesthetic experiences, aesthetic attitude, aesthetic attention, aesthetic judgement, aesthetic value, aesthetic properties, aesthetic stance. To be more generous, we should also include those debates that are discussed in aesthetics journals and books but that are not strictly speaking (or not necessarily) about art. This would include (but, again, not be limited to) questions about picture perception and questions about depiction in general (as not all pictures are art), questions about our engagement with narratives and about narratives in general (not all narratives are art), about fiction and our engagements with them (not all fictions are art), about metaphor, creativity, and so on.

I said that we should detach aesthetics from art, but do so carefully. To demonstrate how this could be done, I use an example that I take to be the paradigmatic example of a genuine aesthetics question: the old question about what constitutes an aesthetic experience. 
Aesthetic experience is neither necessary nor sufficient for the experience of works of art. We can experience works of art in a non-aesthetic manner and we can experience objects other than works of art in an aesthetic manner. If someone attacks me in a museum and there is a small Giacometti sculpture within my reach that I could use to defend myself, I will presumably not experience this sculpture in an aesthetic manner. Yet, it is a work of art. Conversely, we can have aesthetic experience of nature and of ordinary objects (see Carroll 1993 and Irvin 2008 respectively).

In short, although our experiences of works of art often are aesthetic experiences (maybe even paradigmatic instances of aesthetic experiences), they are not necessarily so, nor do aesthetic experiences necessarily concern works of art. I take this to be the general consensus on aesthetic experiences-if we were to deny it, and take the relation between art and aesthetic experience to be tighter, we would be likely to run into one or another historical example of how not to think about aesthetic experiences. I mention two such examples. First, the concept of aesthetic experience has been used to define art. The idea is that those objects are works of art that are supposed to trigger aesthetic experiences or, alternatively, that trigger aesthetic experiences in a suitably informed spectator (see Bell 1914 for a classic exposition). With some alternative definitions of art (see Dickie 1964 and Levinson 1979) as well as the widespread scepticism about the feasibility and desirability of a general definition of art (see, e.g., Lopes 2008), this use of the concept of aesthetic experience seems outdated.

Second, the concept of aesthetic experience has also been taken to be the holy grail of how we should enjoy (great) art: if we enjoy (great) art the right way, we experience the work of art in an aesthetic manner. What seems to follow from this is that if we do not have an aesthetic experience when looking at (great) works of art, we are not doing what we are supposed to be doing: maybe we lack aesthetic sensibility or concentration or training. A more plausible way of thinking about aesthetic experiences would be not to assume that there is a right way of engaging with art, let alone that the right way is to have an aesthetic experience.

This way of (carefully) decoupling questions about art and questions about aesthetics could be generalized to all the other questions about aesthetics. Note that by narrowing the focus of aesthetics and detaching questions about art from it, the surprising main claim of the paper is looking distinctively less surprising: the claim is that it is a promising avenue of research to consider problems in aesthetics, conceived as being distinct from the philosophy of art, to be really about the philosophy of perception. The next step is to analyse what is meant by philosophy of perception.

\subsection{Philosophy of Perception}

The strength of the main claim of this paper clearly depends on how narrowly one interprets the domain of the philosophy of perception. And it is not clear where the boundaries of the philosophy of perception lie (see Nanay 2010c for some discussion 
on this). If we conceive of the philosophy of perception as the ensemble of philosophical questions about perception, then a lot of philosophical questions about perception also cover questions about non-perceptual mental processes.

Here are some examples: What is the difference between perception and belief? What is the difference between sensation and perception? What is the connection between perception and action? What are the similarities and differences between perception and imagination? How does perception justify knowledge? All of these questions are genuine questions in the philosophy of perception but, together, they seem to also cover much of philosophy of mind.

Further, perceptual experience is not to be identified with the sensory stimulation of our sense organs. Much more goes into perception: categorization, conceptualization, and various top-down influences from non-perceptual processes. It would be unwise to ignore these non-sensory aspects of perception when analysing various questions about perception. Thus, the domain of the philosophy of perception must also encompass these higher-order components of our perceptual processing.

When I talk about the philosophy of perception, I have this inclusive concept in mind-an ensemble of philosophical questions connected to perception. This, of course, makes the main claim of the paper look even less radical.

Two important examples of mental processes that play an important role in aesthetics and that are part of the central domain of the philosophy of perception as I conceive of it are attention and sensory imagination. I take it to be relatively uncontroversial that attention is a genuinely perceptual phenomenon (see Prinz 2010, Nanay 2010a, Wolfe 2000, and Prinzmetal and Landau 2008; see also James 1892/1961 and the rich inattentional blindness literature). But the concept of sensory imagination needs some further discussion. Sensory imagination (imagining seeing something) is to be contrasted with propositional imagination (imagining that $\mathrm{x}$ is F). Propositional imagination is a propositional attitude, like beliefs, whereas sensory imagination is by definition 'sensory': perception-like.

Some philosophers of perception even refer to sensory imagination as a quasi-perceptual process (Prinz 2007; Tye 1996; Carruthers 2005), and rightly so: perception and sensory imagination famously have very similar phenomenology: it feels similar to see an apple and to visualize one, as one of the oldest experiments of perceptual psychology demonstrates. In the Perky experiments, subjects looking at a white wall were asked to visualize objects while keeping their eyes open. Unbeknownst to them, barely visible images of the visualized objects were projected on the wall. The surprising finding is that the subjects took themselves to be visualizing the objects, when in fact they were perceiving them (Perky 1910; Segal 1972; Segal and Nathan 1964). The standard interpretation of this experiment is that perceiving and visualizing are phenomenally very similar-in fact they are, at least in these circumstances, indistinguishable (but see Hopkins's 2012 criticism and Nanay's 2012 b response). Some have argued that the content of sensory imagery is also similar to perceptual content (and this may explain the similar phenomenology) (Currie 1995a: 36-7; Currie and Ravenscroft 2002: 27; Noordhof 2002). For these reasons, mental imagery and sensory imagination have been considered to be 
part of the domain of the philosophy of perception. Philosophy of perception is not only about perceptual, but also about quasi-perceptual processes.

And the concept of sensory imagination has played an important role in a number of different debates in aesthetics. Three examples (there are others concerning our engagements with literary narratives or literature in general): first, a grand contemporary debate in aesthetics, and one I will return to in the next section, is about depiction. One distinctive and influential position in this debate is that when we look at pictures, we engage with a complex episode of sensory imagination: we imagine our seeing the picture surface to be our seeing the depicted object (Walton 1973, 1990, 2002; Maynard 1994, forthcoming). Second, it has been argued that our engagement with fiction is an imaginative one and our strong emotional investment in fictional works can be explained with the help of this imaginative engagement (Walton 1978, 1990, 1997; Gendler and Kovakovich 2005; Goldman 2006; Neill 1991; but see also the reservations of Matravers 1997).

Third, our identification with characters in a movie or in a play is also often explained with the help of sensory imagination: the general idea is that when I identify with Hamlet, I imagine Hamlet from the inside (Currie 1995b: 153; Walton 1990: 255, 344; Wollheim 1974: 187, 1987: 103, 129; Smith 1995, 1997; but see the reservations of Carroll 1990: 88-96, 2001: 306-16). Just what this 'imagining from the inside' consists in is not clear: maybe imagining having Hamlet's experiences (Walton 1990: 344), maybe imagining myself in Hamlet's situation (Gaut 1998, 1999. See also Smith 1759/2002 for a historical predecessor of this idea and Nanay 2010b for discussion; on why this not obviously sensory episode may nonetheless be an instance of sensory imagination, see Williams 1966, Kind 2001, Baron-Cohen 2007, and Byrne 2007; cf. Chalmers 2002).

All of these three claims have been criticized, but what matters from our point of view is that they all count as claims within the domain of the philosophy of perception: they are about the quasi-perceptual process of sensory imagination. If we conceive of the philosophy of perception in the way that I proposed-as encompassing questions about attention, sensory imagination, and visual imagery-then the main claim of this paper loses quite a bit from its initial radical appearance.

But some will undoubtedly find this use of the concept of the philosophy of perception too liberal. They can read the title and the main claim of the paper to be about the relation between aesthetics and perception-related issues in the philosophy of mind. If the reader found the claim that it is a promising avenue of research to consider problems and debates in aesthetics to be really about philosophy of mind easier to swallow, I'd be happy to concede the label. Importantly, all the consequences I draw in sections 5.5 and 5.6 would still follow from this claim.

\subsection{Normative versus Descriptive Claims}

After all these clarifications, it is still not clear why should anyone be tempted to accept the main claim of this paper: that it is a promising avenue of research to consider 
debates and problems in aesthetics to be about the philosophy of perception. What is promising about it? And on what basis should we consider it promising? My strategy is to argue that:

(i) some of the most productive and relevant debates in aesthetics have been, and are, about the philosophy of perception and the ones that are not particularly productive or relevant are not, and

(ii) the success of this research direction in the present and recent past gives us some (not overwhelming) reason to follow this research direction in the future.

Let's start with (ii). To take a Lakatosian line, we can talk about progressive and degenerative scientific research programmes (Lakatos 1970, 1974). A scientific research programme is a temporal sequence of a set of scientific theories. A progressive research programme does not contradict any new data and makes new predictions and new explanations. A degenerative one sometimes does contradict new data and makes no (or hardly any) new predictions and new explanations. If a degenerative research programme contradicts new data, this does not falsify the research programme: there are many ways of modifying the research programme in such a way that the contradiction disappears. These modifications, however, involve adding to the 'core' of the research programme extra, ad hoc, assumptions that serve only one purpose: to explain away the contradiction. These extra assumptions constitute the 'protective belt' of a degenerative research programme. The thicker the protective belt, the more likely it is that a research programme is degenerative. The more new predictions and explanations a research programme provides, the more likely it is that it is progressive (Nanay 2010e, 2011c). Lakatos argues that it is often worth being loyal to a degenerative research programme for some time (as it may manage to recover), though if there is an alternative, progressive research programme on the horizon, the rational thing to do is to jump ship and join the progressive one.

A similar distinction can be made between progressive and degenerative philosophical research programmes, including philosophical research programmes in aesthetics. A philosophical research programme is, like a scientific research programme, not a theory, but a temporal sequence of theories that share some important core assumptions. Physicalism or utilitarianism are possible examples for philosophical research programmes. A progressive philosophical research programme would be able to explain and predict new data-in this case, not necessarily empirical data. If a philosophical research programme can, for example, be applied successfully to a new, so far unconsidered subfield, or if it can explain a new, so far unconsidered phenomenon, it is likely that it is progressive. If it faces numerous objections that it can avert only by postulating ad hoc assumptions, the sole purpose of which is to explain away these objections, then it is likely to be a degenerating philosophical research programme.

My claim is that many, or even most, progressive research programmes in recent research in aesthetics have been relying heavily on the philosophy of perception and using its methodological and conceptual apparatus. Thus, the rational strategy for 
the future is to consider joining this research programme. If I manage to establish the descriptive claim about the past and present of the state of aesthetics (my claim (i) above), we can use these Lakatosian considerations to establish that it is a promising avenue of research to consider problems and debates in aesthetics to be really about the philosophy of perception.

But is it true that many, or even most, recent progressive research programmes in aesthetics have been relying heavily on the philosophy of perception and using its methodological and conceptual apparatus? Is (i) true? It is important that the claim I made is that many, maybe even most, and some of the most important debates in aesthetics have been using the methodological and conceptual apparatus of the philosophy of perception. I do not claim that all of them have.

Let us take the example of the debates about aesthetic experiences again. We have seen a very clear candidate for a degenerative research project here, the core of which is that aesthetic experiences have something to do with the essence of art. Remember the suggestion that we could define art with reference to aesthetic experiences: those objects are works of art that are supposed to trigger aesthetic experiences or, alternatively, that trigger aesthetic experiences in a suitably informed spectator (see Bell 1914 for a classic exposition and Greenberg 1961 for a more recent and much more influential version of this claim).

The claim that aesthetic experiences have something to do with the essence of art has been facing some serious objections and potential counter-examples. There are clear examples for works of art that have very little to do with aesthetic experiences. They are not supposed to trigger aesthetic experiences, not even (or especially not) in suitably informed spectators. Duchamp's ready-mades or some recent examples of conceptual art are often-cited examples. In fact, those who urge the distinction between aesthetics and philosophy of art that I elaborated on in section 5.2 are keen to emphasize that aesthetic experience is just one of many ways of relating to artworks and a not particularly important or relevant one in the contemporary art world.

The philosophical research programme that takes aesthetic experiences to have something to do with the essence of art is not falsified by these counter-examples. There are some extra assumptions that they can and do make in order to account for these apparent counter-examples. The main strategy here is to deny that these alleged works of art are in fact works of art (or that they are good works of art). ${ }^{1}$ Greenberg made the most famous such gesture when he denounced Duchamp, claiming that his ready-mades are not art, but even if they are to be considered art, they are definitely not great art. What role does this extra assumption play in the philosophical research programme? The only role it plays is to save the research programme from potentially fatal counter-examples. Thus, it

\footnotetext{
${ }^{1}$ It would also be possible to counter these objections by broadening the scope of what is meant by aesthetic experience (to include the prescribed experience of conceptual art). While we may have independent reasons to broaden the scope of what is meant by aesthetic experiences (Shelley 2003), this strategy does not seem too promising in the present context: if the concept of aesthetic experience covers conceptual art, the worry is that it would need to be so broad that it could not be used to define art (or good art).
} 
AQ: Vivas 1959 is not in the list of References. Also cited on p. 16.

AQ: Kriegel 2007 is not in the list of References; please supply details.
108

is to be considered part of the increasingly exploited protective belt of this philosophical research programme. But a growing protective belt with no new explanations and predictions is exactly what characterizes a degenerative research programme.

Take the alternative approach to aesthetic experience. There seem to be three kinds of theories of aesthetic experience that are very different from one another, but they share some basic ('core' as Lakatos would say) assumptions that make them all belong to the same research programme (remember, a research programme is a temporal sequence of a set of various different theories). The most important such core assumption is that the difference between aesthetic and non-aesthetic experiences is something we can discover if we pay attention to our perceptual processes.

More specifically, these three kinds of theories are the following. First, one can define aesthetic experiences in terms of the properties these experiences represent (see, for example, Beardsley 1981: 456-70; Carroll 2001: 60. See also Carroll 2000: 207 and Carroll 2006). Second, one can define aesthetic experiences in terms of the role these experiences play in our general mental processing (see, for example, Iseminger 1981, 2006: 99; Levinson 1996, 2014). And third, one can define aesthetic experience in terms of the intrinsic properties of these experiences (see, for example, Stolnitz 1960; Bullough 1912; Vivas 1959. The general idea goes back to Kant-see Zangwill 1992 for an analysis of the Kantian origins of this concept of aesthetic experience, as well as Dickie 1964 and Zemach 1997 for criticism).

All of these three categories consist of a number of importantly different theories, but what matters for our purposes is that all of them make an important assumption about the nature of the debate, namely, that it is a debate about philosophy of perception.

If the difference between aesthetic and non-aesthetic experiences is a matter of which properties these experiences represent, then we need to examine what properties can and cannot be represented by experiences in general and perceptual experiences in particular. This very question has recently been one of the most intensely discussed issues in contemporary philosophy of perception. Beliefs can represent their objects as having pretty much any property. Experiences, in contrast, represent their object as having a limited set of properties. Some plausible candidates include having a certain shape, size, colour, and spatial location. The list may be extended but it will not encompass all properties. The property of having been made in 2008 in Malaysia is unlikely to be represented in a perceptual experience.

The question then is about which properties are represented in perception and which ones are not. A couple of quick examples: it has been argued that we perceive objects as trees and tables (Siegel 2006), as being causally efficacious (Siegel 2005, 2009), as edible, climbable, or Q-able in general (Nanay 2012a, 2013a, 2013b), as agents (Scholl and Tremoullet 200o), as having some kind of normative character or value (Kelly 2010; Matthen 2010), as having dispositional properties (Nanay 2011b), as having moral value (Kriegel 2007) and as affording certain actions (for very different versions of this claim, see Gibson 1966, 1979; Bach 1978, esp. p. 368; Jeannerod 1988, 
1997, 1994, esp. section 5; Jacob and Jeannerod 2003, esp. pp. 202-4, Humphreys and Riddoch 2001; Riddoch et al. 1998, esp. p. 678).

In short, the attributed properties account of aesthetic experience heavily relies on one of the most contested issues in the philosophy of perception. If what is distinctive about aesthetic experiences is the property they represent, then we need to know what properties experiences in general can represent (and what properties they cannot). Let us take Carroll's 'deflationary' account as an example. Carroll argues that 'If an experience of an artwork is a matter of [...] the detection of its aesthetic and/or expressive qualities, then it is an aesthetic experience' (Carroll 2001: 60). Given that at least some of the 'aesthetic and/or expressive' properties seem to be dispositional properties, this claim is intertwined with the debate in the philosophy of perception literature about whether perceptual experiences can represent dispositional properties (see Nanay 2011 b for a summary).

The second set of theories defines aesthetic experience in terms of the role this experience plays in our mental life. Some of the proponents of this approach talk explicitly about perception in this context. Here is Jerrold Levinson's definition: 'Aesthetic experience is experience involving aesthetic perception of some object, grounded in aesthetic attention to the object, and in which there is a positive hedonic, affective, or evaluative response to the perception itself and/or the content of that perception' (Levinson 2014: section 5). Although what makes an experience aesthetic is the connection between a perceptual episode and a non-perceptual mental process, this connection is nonetheless a proper subject for philosophers of perception.

The third set of theories looks for intrinsic properties that all and only aesthetic experiences have, and the most important candidate is what is referred to as 'aesthetic attention'-attention to an object or some of its features that is at the same time disinterested or detached (Vivas 1959: 227; Stolnitz 1960:33-4). Needless to say, that concept of attention is also very much part of the conceptual apparatus of the philosophy of perception.

My aim here was not to argue that aesthetic experiences are necessarily perceptual or that only perceivable entities can be experienced aesthetically. Large-scale narrative structure or mathematical proofs can be experienced aesthetically, but they are not perceivable. Although the point has been made that they are represented by virtue of mental (often visual) imagery (see esp. Mancosu 2005), the main point here is that an account of aesthetic experience needs to be rooted in the philosophy of perception.

It is an interesting and complex question whether aesthetic experiences are necessarily perceptual experiences, but everything I say in this paper is neutral as to whether this is the case. What I am, however, committed to is that the only way to decide whether aesthetic experiences are necessarily perceptual experiences is by appealing to the philosophy of perception. And, as we have seen, the scope of the philosophy of perception is much wider than just the question of what is perceived. 
AQ: "Budd 1992 " - there is only Budd 1995 in the list of References; please could you resolve the year discrepancy?

AQ:

"Wollheim $1980 \ldots 1998$, 2003" these three titles are missing from the list of References. Please could you provide details?
So much for aesthetic experiences. Let us take the question of depiction as a second example. One grand debate in aesthetics is about the nature of depiction: about what makes pictures pictures. There are three different approaches to answering this question: (a) Pictures and only pictures have certain syntactic properties (Goodman 1968; Kulvicki 2006); (b) Pictures and only pictures have certain semantic properties (most importantly, resemblance to the depicted scene) (Peacocke 1987; Budd 1992; Abell 2009); and (c) Pictures and only pictures are the things that trigger a certain perceptual (or quasi-perceptual) state in suitable observers, a state that is often labelled 'seeing-in' (Wollheim 1980, 1987, 1998; Walton 1990, 2002; Hopkins 1998; Lopes 1996, 2005; Maynard 1994; Gombrich 1960; Nanay 2004, 2005, 2010d; Matthen 2005; Levinson 1998; Feagin 1998).

Approach (c) assumes a philosophy of perception framework, whereas (a) and (b) do not. Although we have no justification for believing that (a) and (b) are degenerative, (c) is clearly progressive, where various theories belonging to this research programme are being used to explain various new forms of depiction (such as computer art; see, e.g., Lopes 2009) or new features of picture perception (such as the question of inflection; see Podro 1991, 1998; Lopes 2005; Hopkins 2010; Nanay 2010d).

These are only two examples (aesthetic experience and depiction), but there are many more debates in aesthetics where the approach based on the philosophy of perception seems to be the least degenerative research programme. Some further examples include the paradox of fiction, questions about identification, metaphor or creativity. It may be more contentious, but the analysis could also be extended to debates about aesthetic properties, which are almost always defined with reference to some perceptual capacity or another. Nick Zangwill (2011) points out that it has been widely assumed by all parties in the aesthetics properties literature that aesthetic properties are perceived or perceivable. Zangwill himself disagrees with this assumption (see esp. pp. 10-11), but it is important to note that my claim is that the debate about aesthetic properties uses the conceptual apparatus of the philosophy of perception and this can be true even if it turns out that aesthetic properties are not necessarily perceivable properties (as Zangwill suggests). In fact, Zangwill's own argument relies on various debates about the philosophy of perception (more specifically, about the relation between perception and subjectivity).

Aesthetic value is an interesting potential counter-example, because it is sometimes considered to be the big question in aesthetics. Here, we need to make a distinction between the role the concept of value plays in the philosophy of art and in aesthetics. In the philosophy of art, some of the most basic (and oldest) questions about the difference between good and bad art are indeed very difficult to raise without the concept of value, but as we have detached the philosophy of art from aesthetics, one may wonder what role the concept of aesthetic value plays in aesthetics. It does play a very important role in answering the following question: why do we value aesthetic experiences? Why do we pay a lot of money to have them? (see Levinson 1999, for example). But it could be argued that this question is really a question about certain properties of 
certain experiences. Some of our experiences are 'aesthetic' (whatever that means) and these experiences also seem to be intrinsically valuable. Explaining why experiences if they have a certain property (being aesthetic) also have another property (being intrinsically valuable) is an explanatory project about certain properties of certain experiences - arguably a topic for philosophers of perception.

It is also important to note that my claim was that many, maybe even most traditional problems in aesthetics have in fact been about the philosophy of perception. I do not claim that all questions in aesthetics have been dominated by the philosophy of perception. The debate about aesthetic realism, for example, has not. It is worth noticing, however, that many of both the realist and the anti-realist arguments rely on various considerations from the philosophy of perception, especially with regards to the discussion of aesthetic disagreements (starting with Hume's key and thong argument).

A final objection: hasn't conceptual art demonstrated that the perceptual is not everything in art? If so, putting so much emphasis on perception (or even quasi-perceptual processes) may ignore these recent developments in art history. My answer is that conceptual art may or may not have demonstrated this, but that is strictly speaking irrelevant for establishing claims about aesthetics. Remember that questions about aesthetics and questions about the philosophy of art are to be kept separate. There are lots of exciting questions about conceptual art within the domain of the philosophy of art. But it does not follow that it poses new threats to any issue in aesthetics. Remember: not all experiences of artworks have anything to do with the domain of aesthetics: if I sometimes see the Giacometti sculpture as a weapon, there is not much that an aesthetician would need to be worried about. The same is true of our experience of conceptual art (the philosopher of art, on the other hand, has a lot to worry about here).

Now that all qualifications are added to the initial surprising claim, I don't think that it should be particularly controversial. The score is simple. The philosophy of perception is about experiences. Aesthetics is about some special kinds of experiences: aesthetic experiences, the experience we have when looking at pictures, the experience we have when we identify with Hamlet, the experience we have when we engage with fiction, etc. Thus, it shouldn't sound surprising that it is a promising avenue of research to consider debates and problems about aesthetics to be really about the philosophy of perception. Again, some of these may not be perceptual experiences. But, as we have seen, the scope of the philosophy of perception is much wider than the question about the nature of perceptual experiences.

A final clarification: my claim is not that the domain of aesthetics is the perceptual and only the perceptual. The claim is that questions in aesthetics are best tackled with the help of the conceptual apparatus of the philosophy of perception. Lots of questions within the domain of the philosophy of perception are not strictly speaking about the perceptual (just one example: perceptual justification). Thus, if, as I argue, it is a promising avenue of research to consider problems in aesthetics to be really about the 
philosophy of perception, it would not commit us to say that aesthetics is about the perceptual only.

\subsection{Methodological Consequences}

At the beginning of this paper, I quoted Baumgarten, who introduced the concept of aesthetics as 'scientia cognitionis sensitivae': as the science of perception. The reference to science here is both useful and misleading. It is misleading because Baumgarten himself, writing in 1750, was not at all concerned with the various physiological or biological aspects of our perceptual system (see Shusterman 2000, esp. pp. 263-7 for a good analysis of this).

But Baumgarten's reference to science is useful because it reminds us that aesthetics was originally intended to be a branch of science. As the concept and methodology of science has changed since 1750, the concept and methodology of aesthetics should also be updated accordingly. More specifically, there are a lot of empirical findings about our perceptual apparatus that could and should be used by aesthetic theories. And here the connection between aesthetics and the philosophy of perception may become helpful.

In recent years, paying close attention to empirical findings about perception seems to be the norm, rather than the exception. What this means is not that the philosophy of perception has became theoretical vision science. Rather, the philosophical arguments about perception are constrained by, and sometimes supported by, empirical evidence. Even in the case of some of the most genuinely philosophical debates, such as the representationalism versus relationalism debate (Martin 2004, forthcoming; Campbell 2002; Pautz 2010; Siegel 2010; Travis 2004; Brewer 2006, 2011; Crane 2006; Nanay forthcoming a, forthcoming $b$ ), many of the arguments use empirical findings as premises.

If many, maybe even most traditional problems in aesthetics are in fact about the philosophy of perception and can be fruitfully addressed with the conceptual apparatus of the philosophy of perception, then it is also advisable to use the methodology of the philosophy of perception. But, as we have seen, the methodology of the philosophy of perception is at least partly empirically informed methodology. In other words, it is advisable for theories of aesthetics to take the empirical sciences very seriously.

It is important to note that I am not suggesting that we should directly import the results of empirical psychology to aesthetics. What I suggest is that aesthetics should take some new paradigms of the philosophy of perception seriously, ones that are based on a large body of empirical research. However, my aim is not to urge an empirical turn in aesthetics, but to urge a turn in aesthetics towards the philosophy of perception, and this sometimes entails a turn towards empirically informed philosophy of perception.

Take the question of depiction again. There is a huge body of empirical research on picture perception and any philosophical account on 'seeing-in' needs to be able 
to engage with this. Just two examples. There is a lot of research on how our picture perception is influenced when we look at a picture from an oblique angle. It is an odd but important phenomenon that if our position changes in front of the picture, our view of the depicted object does not change (Vishwanath et al. 2005; Pirenne 1970; Polanyi 1970; Wollheim 1980: 215-16; Matthen 2005: 315-17). Even if we look at a picture from an oblique angle, we don't see it as distorted. This is surprising and needs to be explained, as the projection of the depicted object on our retina is very different from the way it is when we look at the picture head-on. Vision scientists have done a lot to explain this difference (Hagen et al. 1978; Busey et al. 1990; Cutting 1987; Halloran 1989; Rogers 1995; Topper 2000; Goldstein 1987; Koenderink et al. 2004), but this very phenomenon puts important constraints on philosophical accounts of 'seeing-in' (see Kulvicki 2006; Nanay 2008, 2011a).

Another set of experiments that is directly relevant for philosophical accounts of 'seeing-in' concerns the picture perception of patients with brain lesion. It turns out that patients with lesion in their dorsal stream (visual agnosia patients) are very bad at seeing things in pictures: they are almost completely incapable of picture perception (see Turnbull et al. 2004 and Westwood et al. 2002). And at least some patients with lesion in their ventral stream (optic ataxia patients), while capable of perceiving pictures (or at least recognizing that they perceive pictures), are very bad at evaluating the length of depicted lines or the size of depicted figures (Jeannerod et al. 1994: 370, see also Jeannerod 1997: 62). Again, any philosophical account of 'seeing-in' needs to be consistent with these findings, and, ideally, a philosophical account of 'seeing-in' would also be able to explain the malfunctioning of our picture perception in the case of visual agnosia and optic ataxia.

Here is an account of seeing-in that is consistent with, and explains, these empirical results (Nanay 2008, 2011a). I have argued that it is constitutive of picture perception that our ventral subsystem attributes properties to the depicted scene, whereas our dorsal subsystem attributes properties to the picture surface. This duality elucidates Richard Wollheim's concept of the 'twofoldness' of our experience of pictures: the 'visual awareness not only of what is represented but also of the surface qualities of the representation' (Wollheim 1980: 214-15). Note that this genuinely philosophical claim about the way to interpret and substantiate Wollheim's claims about twofoldness is both consistent with, and also explains, the empirical findings about picture perception in visual agnosia and optic ataxia patients. This is a potential example for how the interaction between philosophical questions about aesthetics and the empirical sciences would look if we took the philosophy of perception side of aesthetics seriously.

Relying on empirical data has not been the norm in aesthetics (although there are exceptions; see Kulvicki 2006; Lopes 2005, 2010; Matthen 2005; Nanay 2008, 2011a; Pignocchi 2010, just to mention a few; see also Lopes and Bergeron 2011). But given that some branches of the philosophy of perception made significant advances as a result of their close connection with the empirical sciences, if aesthetics were to use similar methodology, we could expect similar advances in at least some old aesthetic debates. 


\subsection{Conclusion: Implications with Regard to the Place of Aesthetics among the Philosophical Disciplines}

Philosophy has been traditionally divided up into two subfields, which are often labelled 'metaphysics and epistemology, broadly construed' and 'value theory'. The former includes, besides metaphysics and epistemology, philosophy of mind, philosophy of perception, philosophy of language, logic, and often even philosophy of science and of religion. The latter includes ethics, social and political philosophy, and aesthetics.

I never really understood why aesthetics is placed in the 'value theory' bag-there are, of course, questions about aesthetic value, but they are either metaphysical-realism versus anti-realism about aesthetic value-or broadly epistemological-how we can judge whether an object has aesthetic value. Some may argue that questions about aesthetic value mirror questions about moral value in ethics, but one may counter this argument by pointing out that the questions about aesthetic value that do mirror questions about moral value are the ones in metaethics, which, arguably, falls squarely in the 'metaphysics and epistemology, broadly construed' bag.

If the argument I presented here is correct, then we need to do some relabelling. If it is a promising avenue of research to consider problems and debates in aesthetics to be really about philosophy of perception, and if philosophy of perception is a subfield of 'metaphysics and epistemology, broadly construed, then we have no reason to keep aesthetics in the 'value theory' bag. Whether this relabelling would improve or damage the public image of aesthetics among other philosophers is a question I would like to leave to the reader...

\section{References}

Abell, Catharine (2009). Canny Resemblance. Philosophical Review, 118: 183-223.

Bach, Kent (1978). 'A Representational Theory of Action', Philosophical Studies, 34: 361-79.

Baron-Cohen, Simon (2007). 'The Biology of the Imagination', in R. H. Wells and J. McFadden (eds), Human Nature? London: The Continuum International Publishing Group, 103-10.

Beardsley, Monroe (1981). Aesthetics, 2nd edn. Indianapolis: Hackett.

Bell, Clive (1914). Art. London: Chatto and Windus.

Brewer, Bill (2006). 'Perception and Content', European Journal of Philosophy, 14: 165-81.

Brewer, Bill (2011). Perception and its Objects. Oxford: Oxford University Press.

Budd, Malcolm (1992). 'On Looking at a Picture', in J. Hopkins and A. Savile (eds), Psychoanalysis, Mind and Art. Oxford: Blackwell, 259-80.

Bullough, Edward (1912). "Physical Distance" as a Factor in Art and as an Aesthetic Principle', British Journal of Psychology, 5: 87-98.

Busey, T. A., N. P. Brady, and J. E. Cutting (1990). 'Compensation is Unnecessary for the Perception of Faces in Slanted Pictures', Perception \& Psychophysics, 48/1: 1-11.

Byrne, Alex (2007). 'Possibility and Imagination', Philosophical Perspectives, 21: 125-44.

Campbell, J. (2002). Reference and Consciousness. Oxford: Oxford University Press.

Carroll, Noël (1990). The Philosophy of Horror. London: Routledge. 
Carroll, Noël (1993). 'On Being Moved by Nature: Between Religion and Natural History', in S. Kemal and I. Gaskell (eds), Landscape, Natural Beauty and the Arts. Cambridge: Cambridge University Press, 244-66.

Carroll, Noël (2000). 'Art and the Domain of the Aesthetic', British Journal of Aesthetics, 40: $191-208$.

Carroll, Noël (2001). 'Four Concepts of Aesthetic Experience', in Beyond Aesthetics. Cambridge: Cambridge University Press, 41-62.

Carroll, Noël (2002). 'Aesthetic Experience Revisited', British Journal of Aesthetics, 42: 145-68.

Carroll, Noël (2006). 'Aesthetic Experience: A Question of Content', in Matthew Kieran (ed.), Contemporary Debates in Aesthetics and the Philosophy of Art. London: Blackwell, 69-97.

Carruthers, Peter (2005). 'Conscious Experience versus Conscious Thought', in Consciousness: Essays from a Higher-Order Perspective. Oxford: Clarendon Press, 134-56.

Chalmers, David (2002). 'Does Conceivability Entail Possibility?', in Tamar Szabó Gendler and John Hawthorne (eds), Conceivability and Possibility. Oxford: Oxford University Press, 145-200.

Crane, Tim (2006). 'Is There a Perceptual Relation?', in T. Gendler and J. Hawthorne (eds), Perceptual Experience. Oxford: Oxford University Press, 126-46.

Currie, Gregory (1995a). 'Visual Imagery as the Simulation of Vision', Mind and Language, 10: $25-44$.

Currie, Gregory (1995b). Image and Mind: Film, Philosophy, and Cognitive Science. Cambridge: Cambridge University Press.

Currie, Gregory and Ian Ravenscroft (2002). Recreative Minds: Imagination in Philosophy and Psychology. Oxford: Oxford University Press.

Cutting, J. E. (1987). 'Rigidity in Cinema Seen from the Front Row, Side Aisle', Journal of Experimental Psychology: Human Perception and Performance, 13: 323-34.

Dickie, George (1964). 'The Myth of Aesthetic Attitude', American Philosophical Quarterly, 1: 56-65.

Dickie, George (1974). Art and the Aesthetic. Ithaca, NY: Cornell University Press.

Feagin, Susan L. (1998). 'Presentation and Representation', Journal of Aesthetics and Art Criticism, 56: $234-40$.

Gaut, Berys (1998). 'Imagination, Interpretation, and Film', Philosophical Studies, 89: 331-41.

Gaut, Berys (1999). 'Identification and Emotion in Narrative Film', in Carl Plantinga and Greg M. Smith (eds), Passionate Views: Thinking about Film and Emotion. Baltimore: Johns Hopkins University Press, 200-16.

Gendler, Tamar Szabó and Karson Kovakovich (2005). 'Genuine Rational Fictional Emotions', in Matthew Kieran (ed.), Contemporary Debates in Aesthetics and the Philosophy of Art. London: Blackwell, 241-53.

Gibson, James J. (1966). The Senses Considered as Perceptual Systems. Boston: Houghton Mifflin. Gibson, James J. (1979). An Ecological Approach to Visual Perception. Boston: Houghton Mifflin.

Goldman, Alvin (2006). 'Imagination and Simulation in Audience Responses to Fiction', in Shaun Nichols (ed.), The Architecture of the Imagination. Oxford: Oxford University Press, 41-56.

Goldstein, E. B. (1987). 'Spatial Layout, Orientation Relative to the Observer, and Perceived Projection in Pictures Viewed at an Angle', Journal of Experimental Psychology Human Perceptual Performance, 13: 256-66. 
Gombrich, Ernst (1960). Art and Illusion. New York: Pantheon.

Goodman, Nelson (1968). Languages of Art. Indianapolis: Bobbs Merrill.

Greenberg, Clement (1961). Art and Culture: Critical Essays. Boston: Beacon Press.

Hagen M. A., R. Glick, and B. Morse (1978). 'Role of Two-Dimensional Surface Characteristics in Pictorial Depth Perception', Perception and Motor Skills, 46: 875-81.

Halloran, T. O. (1989). 'Picture Perception is Array Specific: Viewing Angle versus Apparent Orientation', Perception \& Psychophysics, 45: 467-82.

Hopkins, Robert (1998). Picture, Image and Experience: A Philosophical Inquiry. Cambridge: Cambridge University Press.

Hopkins, Robert (2010). 'Inflected Pictorial Experience: Its Treatment and Significance', in Catharine Abell and Katarina Bantilaki (eds), Philosophical Perspectives on Depiction. Oxford: Oxford University Press, 151-80.

Hopkins, R. (2012). 'What Perky Did Not Show', Analysis, 72: 431-9.

Humphreys, Glyn W. and M. Jane Riddoch (2001). 'Detection by Action: Neuropsychological Evidence for Action-Defined Templates in Search', Nature Neuroscience, 4: 84-8.

Irvin, Sherri (2008). 'The Pervasiveness of the Aesthetic in Ordinary Experience', British Journal of Aesthetics, 48: 29-44.

Iseminger, Gary (1981). 'Aesthetic Appreciation', Journal of Aesthetics and Art Criticism, 39: 389-97.

Iseminger, Gary (2006). 'The Aesthetic State of Mind', in Matthew Kieran (ed.), Contemporary Debates in Aesthetics and the Philosophy of Art. London: Blackwell, 98-110.

Jacob, Pierre and Marc Jeannerod (2003). Ways of Seeing: The Scope and Limits of Visual Cognition. Oxford: Oxford University Press.

James, William (1892/1961). Psychology: The Briefer Course, ed. Gordon Allport. New York: Harper \& Row.

Jeannerod, M. (1988). The Neural and Behavioral Organization of Goal-Directed Movements. New York: Oxford University Press.

Jeannerod, M. (1994). 'The Representing Brain: Neural Correlates of Motor Intention and Imagery', Behavioral and Brain Sciences, 17: 187-245.

Jeannerod, M. (1997). The Cognitive Neuroscience of Action. Oxford: Blackwell.

Jeannerod, M., J. Decety, and F. Michel (1994). 'Impairment of Grasping Movements Following a Bilateral Posterior Parietal Lesion', Neuropsychologia, 32: 369-80.

Kelly, Sean (2010). 'The Normative Nature of Perceptual Experience', in Bence Nanay (ed.), Perceiving the World. New York: Oxford University Press, 146-59.

Kind, Amy (2001). 'Putting the Image Back to Imagination', Philosophy and Phenomenological Research, 62: 85-109.

Koenderink, J., A. van Doorn, A. Kappers, and J. Todd (2004). 'Pointing Out of the Picture', Perception, 33: 513-30.

Kriegel, Uriah (2007). 'The Phenomenologically Manifest', Phenomenology and the Cognitive Sciences, 6: 115-36.

Kulvicki, John (2006). On Images: Their Structure and Content. Oxford: Oxford University Press.

Lakatos, Imre (1970). 'Falsification and the Methodology of Scientific Research Programmes', in Imre Lakatos and Alan Musgrave (eds), Criticism and the Growth of Knowledge. Cambridge: Cambridge University Press, 91-196. 
Lakatos, Imre (1974). 'Science and Pseudoscience', in Godfrey Vesey (ed.), Philosophy in the Open. Milton Keynes: Open University Press, 96-102.

Levinson, Jerrold (1979). 'Defining Art Historically', British Journal of Aesthetics, 19: 232-50.

Levinson, Jerrold (1996). 'Pleasure and the Value of Works of Art', in The Pleasures of Aesthetics. Ithaca, NY: Cornell University Press, 11-24.

Levinson, Jerrold (1998). 'Wollheim on Pictorial Representation', Journal of Aesthetics and Art Criticism, 56: 227-33.

Levinson, Jerrold (2014). 'Toward a Non-Minimalist Conception of Aesthetic Experience', in Aesthetic Pursuits. Oxford: Oxford University Press.

Lopes, Dominic McIver (1996). Understanding Pictures. Oxford: Oxford University Press.

Lopes, Dominic McIver (2005). Sight and Sensibility. Oxford: Oxford University Press.

Lopes, Dominic McIver (2008). 'Nobody Needs a Theory of Art', Journal of Philosophy, 105: 109-27. Lopes, Dominic McIver (2009). A Philosophy of Computer Art. London: Routledge.

Lopes, Dominic McIver (2010). 'Picture This: Image-Based Demonstratives', in Catharine Abell and Katarina Bantilaki (eds), Philosophical Perspectives on Depiction. Oxford: Oxford University Press, 52-80.

Lopes, Dominic McIver and Vincent Bergeron (2011). 'Aesthetic Theory and Aesthetic Science: Prospects for Integration', in Steven Palmer and Arthur Shimamura (eds), Aesthetic Science: Connecting Minds, Brains, and Experience. Oxford: Oxford University Press, 63-79.

Mancosu, Paolo (2005). 'Visualization in Logic and Mathematics', in P. Mancosu, K. Jørgensen, and S. Pedersen (eds), Visualization, Explanation and Reasoning Styles in Mathematics. New York: Springer, 13-30.

Martin, M. G. F. (2004). 'The Limits of Self-Awareness', Philosophical Studies, 120: 37-89.

Martin, M. G. F. (forthcoming). Uncovering Appearances. Oxford: Oxford University Press.

Matravers, Derek (1997). 'The Paradox of Fiction: The Report vs. the Perceptual Model', in M. Hjort and S. Laver (eds), Emotion and the Arts. Oxford: Oxford University Press, 78-92.

Matthen, Mohan (2005). Seeing, Doing and Knowing: A Philosophical Theory of Sense Perception. Oxford: Oxford University Press.

Matthen, Mohan (2010). 'How Things Look (and What Things Look That Way)', in Bence Nanay (ed.), Perceiving the World. New York: Oxford University Press, 226-53.

Maynard, Patrick (1994). 'Seeing Double', Journal of Aesthetics and Art Criticism, 52: 155-67.

Maynard, Patrick (forthcoming). 'What's So Funny? Artefacts for Imagining'.

Nanay, Bence (2004). 'Taking Twofoldness Seriously: Walton on Imagination and Depiction', Journal of Aesthetics and Art Criticism, 62: 285-9.

Nanay, Bence (2005). 'Is Twofoldness Necessary for Representational Seeing?', British Journal of Aesthetics, 45: 263-72.

Nanay, Bence (2008). 'Picture Perception and the Two Visual Subsystems', in B. C. Love, K. McRae, and V. M. Sloutsky (eds), Proceedings of the 3oth Annual Conference of the Cognitive Science Society (CogSci 2008). Hillsdale, NJ: Lawrence Erlbaum, 975-80.

Nanay, Bence (2009). 'Narrative Pictures', Journal of Aesthetics and Art Criticism, 67: 119-29.

Nanay, Bence (2010a). 'Attention and Perceptual Content', Analysis, 70: 263-70.

Nanay, Bence (2010b). 'Adam Smith's Concept of Sympathy and its Contemporary Interpretations', Adam Smith Review, 5: 85-105. Also published as a book: Vivienne Brown and Sam Fleischacker (eds), The Philosophy of Adam Smith (London: Routledge, 2010), 85-105. 
Nanay, Bence (2010c). 'Philosophy of Perception-The New Wave', in Bence Nanay (ed.), Perceiving the World: New Essays on Perception. New York: Oxford University Press, 3-12.

Nanay, Bence (2010d). 'Inflected and Uninflected Perception of Pictures', in Catharine Abell and Katarina Bantilaki (eds), Philosophical Perspectives on Depiction. Oxford: Oxford University Press, 181-207.

Nanay, Bence (2010e). 'Rational Reconstruction Reconsidered', The Monist, 93: 595-615.

Nanay, Bence (2011a). 'Perceiving Pictures', Phenomenology and the Cognitive Sciences, 10: $461-80$.

Nanay, Bence (2011b). 'Do We Sense Modalities with our Sense Modalities?', Ratio, 24: 299-310.

Nanay, Bence (2011c). 'Popper's Darwinian Analogy', Perspectives on Science, 19: 337-54.

Nanay, Bence (2012a). 'Action-Oriented Perception', European Journal of Philosophy, 20: 430-46.

Nanay, Bence (2012b). 'The Philosophical Implications of the Perky Experiments', Analysis, 72: 439-43.

Nanay, Bence (2013a). Between Perception and Action. Oxford: Oxford University Press.

Nanay, Bence (2013b). 'Success Semantics: The Sequel', Philosophical Studies, 165: 151-65.

Nanay, Bence (2014). Aesthetics as Philosophy of Perception. Oxford: Oxford University Press.

Nanay, Bence (forthcoming a). 'Empirical Problems with Anti-Representationalism', in B. Brogaard (ed.), Does Perception Have Content? New York: Oxford University Press.

Nanay, Bence (forthcoming b). 'The Representationalism versus Relationalism Debate: Explanatory Contextualism about Perception', European Journal of Philosophy.

Neill, Alex (1991). 'Fear, Fiction and Make-Believe', Journal of Aesthetics and Art Criticism, 49/1: 47-56.

Neill, Alex (1996). 'Empathy and (Film) Fiction', in David Bordwell and Noël Carroll (eds), PostTheory: Reconstructing Film Studies. Madison: Wisconsin University Press, 175-94.

Noordhof, Paul (2002). 'Imagining Objects and Imagining Experiences', Mind \& Language, 17: 426-55.

Pautz, Adam (2010). 'An Argument for the Intentional View of Visual Experience', in Bence Nanay (ed.), Perceiving the World. New York: Oxford University Press, 254-309.

Peacocke, Christopher (1987). 'Depiction', The Philosophical Review, 96: 383-410.

Perky, C. W. (1910). 'An Experimental Study of Imagination', American Journal of Psychology, 21: 422-52.

Pignocchi, Alessandro (2010). 'How the Intentions of the Draughtsman Shape the Perception of a Drawing', Consciousness and Cognition, 19: 887-98.

Pirenne, Maurice Henri (1970). Optics, Painting, and Photography. Cambridge: Cambridge University Press.

Podro, Michael (1991). 'Depiction and the Golden Calf', in N. Bryson, M. Ann Holly, and K. Moxey (eds), Visual Theory. New York: Harper Collins, 163-89.

Podro, Michael (1998). Depiction. Cambridge, MA: Harvard University Press.

Polanyi Michael (1970). 'What is a Painting?', British Journal of Aesthetics, 10: 225-36.

Prinz, J. J. (2007). 'All Consciousness is Perceptual', in B. McLaughlin and J. Cohen (eds), Contemporary Debates in Philosophy of Mind. Oxford: Blackwell, 335-57.

Prinz, Jesse (2010). 'How do Perceptual States Become Conscious?', in Bence Nanay (ed.), Perceiving the World: New Essays on Perception. New York: Oxford University Press, 310-32.

Prinzmetal, W. and A. Landau (2008). 'Dissecting Spatial Visual Attention', in V. Coltheart (ed.), Tutorials in Visual Cognition. Hove: Psychology Press, 43-66. 
Riddoch, M. Jane, Martin G. Edwards, and Glyn W. Humphreys (1998). 'Visual Affordances Direct Action: Neuropsychological Evidence from Manual Interference', Cognitive Neuropsychology, 15: 645-93.

Rogers, S. (1995). 'Perceiving Pictorial Space', in W. Epstein and S. Rogers (eds), Perception of Space and Motion. San Diego, CA: Academic Press: 119-63.

Scholl, B. J. and P. D. Tremoulet (2000). 'Perceptual Causality and Animacy', Trends in Cognitive Sciences, 4: 299-309.

Shusterman, R. (2000). Pragmatist Aesthetics. Lanham, MD: Rowman and Littlefield.

Segal, S. J. (1972). 'Assimilation of a Stimulus in the Construction of an Image: The Perky Effect Revisited', in Peter W. Sheehan (ed.), The Function and Nature of Imagery. New York: Academic Press, 203-30.

Segal, S. J. and S. Nathan (1964). 'The Perky Effect: Incorporation of an External Stimulus into an Imagery Experience under Placebo and Control Conditions', Perceptual and Motor Skills, 19: 385-95.

Shelley, J. (2003). 'The Problem of Non-Perceptual Art', British Journal of Aesthetics, 43: 363-78.

Siegel, Susanna (2005). 'The Phenomenology of Efficacy', Philosophical Topics, 33: 65-84.

Siegel, Susanna (2006). 'Which Properties are Represented in Perception?', in T. Gendler and J. Hawthorne (eds), Perceptual Experience. Oxford: Oxford University Press, 481-503.

Siegel, Susanna (2009). 'The Visual Experience of Causation', Philosophical Quarterly, 59: 519-40. Siegel, Susanna (2010). 'Do Visual Experiences Have Contents?', in Bence Nanay (ed.), Perceiving the World. Oxford: Oxford University Press, 333-68.

Smith, Adam (1759/2002). The Theory of Moral Sentiments. Cambridge: Cambridge University Press.

Smith, Murray (1995). Engaging Characters. Oxford: Oxford University Press.

Smith, Murray (1997). 'Imagining from the Inside', in Richard Allen and Murray Smith (eds), Film Theory and Philosophy. Oxford: Oxford University Press, 412-30.

Stolnitz, Jerome (1960). Aesthetics and Philosophy of Art Criticism. New York: Houghton Mifflin. Topper, D. (2000). 'On Anamorphosis: Setting Some Things Straight', Leonardo, 33: 115-24.

Travis, C. (2004). 'The Silence of the Senses', Mind, 113: 57-94.

Turnbull, Oliver H., Jon Driver, and Rosaleen A. McCarthy (2004). '2D But Not 3 D: Pictorial Depth Deficits in a Case of Visual Agnosia', Cortex, 40: 723-38.

Tye, Michael (1996). 'Mental Reality', Journal of Philosophy, 93: 421-4.

Urmson, J. O. (1959). 'Contextualism Reconsidered', Journal of Aesthetics and Art Criticism, 18: $222-40$.

Vartinian, O. (2009). 'Conscious Experience of Pleasure in Art', in M. Skov and O. Vartanian (eds), Neuroaesthetics. Amityville, NY: Baywood, 261-73.

Vishwanath, Dhanraj, Ahna R. Girshick, and Martin S. Banks (2005). 'Why Pictures Look Right When Viewed from the Wrong Place', Nature Neuroscience, 8: 1401-10.

Vivas, E. (1959). 'Contextualism Reconsidered', The Journal of Aesthetics and Art Criticism, 18/2: 222-40.

Walton, Kendall L. (1973). 'Pictures and Make-Believe', Philosophical Review, 82: 283-319.

Walton, Kendall L. (1978). 'Fearing Fictions', Journal of Philosophy, 75/1: 5-27.

Walton, Kendall L. (1990). Mimesis as Make-Believe: On the Foundations of the Representational Arts. Cambridge, MA: Harvard University Press. 
Walton, Kendall L. (1991). 'Reply to Reviewers', Philosophy and Phenomenological Research, 51: 423-7.

Walton, Kendall L. (1997). 'Spelunking, Simulation, and Slime: On Being Moved by Fiction', in Mette Hjort and Sue Laver (eds), Emotion and the Arts. Oxford: Oxford University Press, 37-49.

Walton, Kendall L. (2002). 'Depiction, Perception, and Imagination', The Journal of Aesthetics and Art Criticism, 60: 27-35.

Williams, Bernard (1966). 'Imagination and the Self', Proceedings of the British Academy, 52: $105-24$.

Wolfe J. (2000). 'Visual Attention', in K. K. De Valois (ed.), Seeing, 2nd edn. San Diego, CA: Academic Press, 335-86.

Wollheim, Richard (1974). 'Identification and Imagination', in Richard Wollheim (ed.), Freud: A Collection of Critical Essays. New York: Anchor Press, 172-95.

Wollheim, Richard (1980). 'Seeing-As, Seeing-In, and Pictorial Representation', in Art and its Object, 2nd edition. Cambridge: Cambridge University Press, 205-26.

Wollheim, Richard (1987). Painting as an Art. Princeton: Princeton University Press.

Wollheim, Richard (1998). 'On Pictorial Representation', Journal of Aesthetics and Art Criticism, 56: $217-26$.

Wollheim, Richard (2001). 'On Formalism and Pictorial Organization', Journal of Aesthetics and Art Criticism, 59: 127-37.

Zangwill, Nick (1992). 'UnKantian Notions of Disinterest', British Journal of Aesthetics, 32: 49-52. Zangwill, Nick (2011). 'Music, Essential Metaphor and Private Language', American Philosophical Quarterly, 48:1-16.

Zemach, Eddy (1997). Real Beauty. University Park: Pennsylvania State University Press. 